\title{
CONTRIBUTION OF SOCIAL FACTORS TO OPIATE-INDUCED ACTIVATION IN THE MOUSE
}

\author{
R. J. KATZ and K. SchmaltZ \\ Mental Health Research Institute, Department of Psychiatry, University of Michigan \\ Medical Center, Ann Arbor, MI 48109, U.S.A.
}

(Accepted 23 September 1980)

\begin{abstract}
Summary-Adult male Swiss-Webster mice of varying group size (single, or in groups of 2,3, or 4) were injected with vehicle, or 25 or $50 \mathrm{mg} / \mathrm{kg}$ of morphine sulfate. In comparison with vehicle, morphineinjected mice showed heightened behavioral activity consisting mainly of stereotyped forward locomotion. This motor response was disproportionately enhanced by the presence of conspecifics. This suggests that morphine-induced activation of grouped animals reflects both individual activation responses and the further influence of social factors.
\end{abstract}

Social facilitation and inhibition effects, i.e. increased or decreased performance due to the presence of conspecifics, have been found both in humans and many other species (e.g. ants, roaches, fish, birds, rats, dogs). While mechanisms underlying these effects are not established, social mediation of arousal level and influence of arousal on performance are considered to play important roles (Green and Grange, 1977; Zajonc, 1965; note however Cottrell, 1972). In the present report a novel social facilitation effect is identified, based upon the differential effects of morphine upon the activity of variously sized groups of mice.

Although the ability of morphine to produce activity in mice is well established (e.g. Krueger, Eddy and Sumwalt, 1941), the role of social factors in this response has not been studied. Social factors are known to influence other pharmacological syndromes (reviewed in Robbins, 1977), and the present results suggest that opiates may also share this property.

\section{METHODS}

\section{Subjects}

Adult male Swiss-Webster mice $(n=210)$, $30 \pm 3 \mathrm{~g} /$ mouse were group housed $10 \mathrm{mice} / \mathrm{cage}$ in $8.5 \times 29.5 \times 15 \mathrm{~cm}$ plexiglas cages with food (Teklad $4.0 \%$ rodent diet $\mathrm{S}-0836$ ) and tap water continuously available. Normal $12 \mathrm{hr} / 12 \mathrm{hr}$ day/night cycles (lights on $=0800-2000 \mathrm{hr}$ ) were maintained by automatic programming.

\section{Apparatus and behavioral procedure}

Mice (in all cases cagemates) were placed singly or in groups of 2,3 , or 4 in $51 \times 41 \times 22 \mathrm{~cm}$ cages (Scientific Products Series 70 ) containing fresh pine chip bedding. The cages rested upon commercially

Key words: activity, opiates, morphine, social facilitation. available field-sensitive activity monitors (Stoelting. Chicago, IL), adjusted to within $5 \%$ sensitivity of each other. Four hours habituation in the testing cages preceded the start of the experiment. By hour four, all groups were behaviorally quiescent, and were injected intraperitoneally with drug or vehicle. Injections were $10 \mathrm{ml} / \mathrm{kg}$.

Morphine was administered as the sulfate salt, 25 or $50 \mathrm{mg} / \mathrm{kg}$. with $0.9 \%$ sodium chloride solution serving as injection medium. Throughout all experiments, $50 \mathrm{~dB}$ of masking noise was provided by the continuous operation of air circulating equipment, and lighting was provided by the operation of seven $75 \mathrm{~W}$ fluorescent lights. Further details of apparatus and procedures are provided in previous publications (Katz and Schmaltz, 1979). Recording continued for $2 \mathrm{hr}$ post-injection with data collected in consecutive 10 min intervals.

\section{Statistical analysis}

Unless indicated otherwise data are presented as means and standard errors. Initial analysis was by 3 factor analysis of variance (drug dosage, group size, time) with repeated measures upon the last factor. Further and more direct testing of social facilitation involved the Kolmogorov-Smirnov test. Empirically derived cumulative probability distributions based upon total activity per group per session were compared with a theoretically derived distribution reflecting a linear increase in activity with group size (see below). Kolmogorov-Smirnov tests, against a null hypothesis of a linear activity increase, were carried out individually for the 0,25 and $50 \mathrm{mg} / \mathrm{kg}$ morphineinjected groups.

\section{RESULTS}

Drug-treated mice showed enhanced activity in comparison with vehicle-treated mice. Activity was 

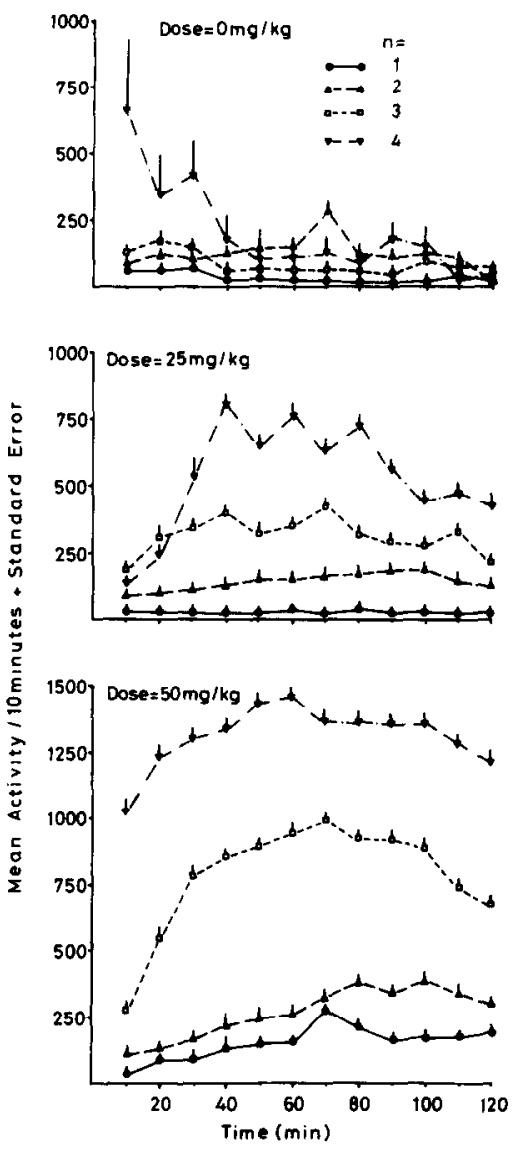

Fig. 1. Effects of three doses of drug $(0,25,50 \mathrm{mg} / \mathrm{kg}$ of morphine) and four housing conditions (1, 2, 3,4 mice/cell) upon behavioral activity. Mice were initially habituated to their cages, then injected with vehicle or drug with recording continuing for twelve additional $10 \mathrm{~min}$ blocks. All data are presented as means and standard errors. Seven determinations were used for each data point. It should be noted that the same degrees of freedom apply to each determination, independently of the number of mice per cage, i.e. single determinations of cage sizes 1 through 4 are stat-

istically the same in their effect upon the analysis.

further enhanced by the presence of other mice. This last effect was dependent upon drug administration. Figure 1 presents the untransformed group means which were used for the initial analysis of variance and subsequently transformed for more direct assess- ment of social facilitation. Transformations were based upon proportions of total activity for all groups. Total activity of all cells collapsed over-time was taken as 1.0 and contributions of cells of group size 1, 2, 3 and 4 were expressed as fractions of the total. It may be seen that while injection of vehicle produced at best a minor initial peak of activity (in groups of 4 mice) only drug injection produced a long-lasting facilitation of activity, particularly in the grouped mice. Analysis of variance indicated statistical reliability beyond $P<0.001$ for all main and interaction effects $(F$ for drug dose $=42.9$, d.f. $=2,72$; $F$ for group size $=33.8$, d.f. $=3.72 ; F$ for time $=7.7$. d.f. $=11,792 ; F$ group size $\times$ dose $=7.9$, d.f. $=6.72$; $F$ group size $\times$ time $=10.1$, d.f. $=22.792 ; F$ dose by time $=2.9$, d.f. $=33,792: \quad F$ three way interaction $=30.0$, d.f. $=66.792$ ). The findings that groups differed, based upon size. and that group size and drug interacted, both support the postulated drugspecific social facilitation effect. Effects related to the time factor will be treated below. More direct tests based upon Kolmogorov-Smirnov tests against the hypothetical linear model indicated that salineinjected mice were not different from the hypothetical distribution $\left(K_{D}=6, P>0.05\right)$ but both druginjected groups were significantly different from the linear model $\left[K_{D}\right.$ in both cases $=14 . P<0.05$ based upon d.f. $=336$ (d.f. based on 12 repeated measurements on 7 groups, each of 4 conditions)]. The proportional cumulative distributions upon which calculations were based are presented in Table 1.

\section{DISCUSSION}

Vehicle-injected mice showed a monotonic increase in activity which was proportional to group size and not reliably different from a predicted linear model; opiate-injected mice showed both increased activity and social facilitation of activity. Indeed, for both drug doses, over $50 \%$ of total activity was due to mice run in groups of four, and roughly $85 \%$ of activity was due to mice run in groups of 3 or 4 . These findings point to a social facilitation effect. As noted above, social effects upon behavior have been reported for other drugs, and effects of isolation upon differential pharmacological responsiveness have also been reported (op. cit.).

Table 1. Mean cumulative proportion of total activity* for morphine-injected mice of variously sized groups

\begin{tabular}{lcccc}
\hline Condition group size $n=$ & 1 & 2 & 3 & 4 \\
\hline Theoretically predicted & 0.10 & 0.30 & 0.70 & 1.00 \\
Drug dose: & & & & \\
$0 \mathrm{mg} / \mathrm{kg}$ & 0.08 & 0.34 & 0.60 & 1.00 \\
$25 \mathrm{mg} / \mathrm{kg} \dagger$ & 0.02 & 0.15 & 0.45 & 1.00 \\
$50 \mathrm{mg} / \mathrm{kg} \dagger$ & 0.06 & 0.17 & 0.39 & 1.00 \\
\hline
\end{tabular}

* Summed across time in all cases.

$+P<0.05$ by Kolmogorov-Smirnov test against theoretically derived and $0 \mathrm{mg} / \mathrm{kg}$ derived cumulative distributions. See text for details. 
The facts that groups differed with respect to time, and that groups, drug and time interacted suggest that whatever the cause of the facilitation, it was not stable throughout the session. Indeed, examination of Figure 1 would seem to point to a particular sensitivity to the effect between 30 and $90 \mathrm{~min}$. At least for the smaller drug dose this does not reflect a peak of drug activity in individual animals. Neither the cause of the social effect nor the basis of its time course are known.

Informal behavioral observations of mice responding to opiates in these and other tests may offer one feature of activity which might explain these effects. Individual mice showed stereotyped forward locomotion. Grouped mice followed each other, often forming a line which would move around the periphery of the cage in a continual fashion. Possibly opiateinjected mice showed both, or a modest degree of forward locomotion and increased following of moving objects, a propensity which would only have been evident with the testing of grouped animals. Facilitation may in part reflect movement by any one mouse which might have provoked further movement (in the form of increased following) by the remaining cagemates.

The present findings are broadly consistent with recent studies by Panksepp and co-workers (Panksepp, Herman, Conner. Bishop and Scott, 1978; Panksepp, Vilberg, Bean, Coy and Kastin, 1978) demonstrating that opiates may be involved in social bonding. Considerably larger doses were used in the present experiment, however. While species and tasks differ, and while no previous attempt has been made to assess social facilitation, the present authors concur with the general conclusions of Panksepp et al. that social effects of various sorts may be mediated by one or more of the endogenous opioid neuropeptides.

Acknowledgements-The editorial assistance of Abe Feingold and statistical assistance of Bob Shea are acknowledged with gratilude. Dr Katz is a Sloan Foundation Fellow in Neuroscience.

\section{REFERENCES}

Cottrell, N. B. (1972). Social facilitation. In: Experimental Social Psychology (McClintock. G. G.. Ed.). Holt Reinhart \& Winston, New York.

Green, R. G. and Grange, J. J. (1977). Drive theory of social facilitation. Twelve years of theory and research. Psychol. Bull. 84: 1267-1288.

Katz, R. J. and Schmaltz, K. (1979). Facilitation of opiate and enkephalin induced activation in the mouse by phenytoin sodium and carbamazepine. Psychopharmacology 65: $65-68$.

Krueger, H., Eddy, N. and Sumwalt, M. (1941). The Pharmacology of the Opium Alkaloids, pp. 1-20. U.S. Government Printing Office. Washington, DC.

Panksepp, J., Herman, B. Conner, R., Bishop. P. and Scott, J. P. (1978). The biology of social attachments: opiates relieve separation distress. Biol. Psychiat. 13: 607-618.

Panksepp, J., Vilberg. T., Bean. N. J., Coy, D. H. and Kastin, A. J. (1978). Reduction of distress vocalization in chicks by opiate like peptides. Brain Res. Bull. 3: 663-667.

Robbins, T. W. (1977). A critique of the methods available for the measurement of spontaneous motor activity. In: The Handhook of Psychopharmacology. Vol. 7; Principles of Behavioral Pharmacology (Iversen, L. L., Iversen, S. D. and Snyder. S. H., Eds), pp. 37-82. Plenum Press, New York.

Zajonc, R. (1965). Social facilitation. Science 149: 269-274. 